\title{
Therapeutic Balloon-Assisted Enteroscopy
}

\author{
Huseyin Aktas Peter B.F. Mensink \\ Department of Gastroenterology and Hepatology, Erasmus MC, University Medical Center, Rotterdam, \\ The Netherlands
}

\section{Key Words}

Balloon-assisted enteroscopy $\cdot$ Double balloon enteroscopy · Single balloon enteroscopy · Endoscopic therapy $\cdot$ Enteroscopy, intervention

\begin{abstract}
Since the introduction of the first balloon-based enteroscopic technique in 2001, therapeutic balloon-assisted enteroscopy (BAE) using either the single or double balloon enteroscopy technique (respectively SBE and DBE) has evolved rapidly. Argon plasma coagulation (APC), polypectomy, dilation therapy of strictures, and therapy of the pancreatico-biliary system in patients with surgical altered proximal intestinal anatomy: all have been successfully introduced to treat pathological findings in all segments of the small bowel. The clinical impact of treatment of vascular malformations, strictures caused by chronic inflammation (especially Crohn's disease) and polypectomy therapy (especially in the Peutz-Jeghers syndrome) seems evident. The decrease of, often repeated, surgical therapy after successful therapeutic BAE in the latter 2 patient groups appears to be a big step forward in treatment. The development of newer enteroscopes, specialized equipment and improved sedation of patients adds positively to the clinical management of undergoing therapeutic BAE. The overall complication rate of therapeutic BAE seems acceptable, but is higher compared to therapeutic colonoscopy which needs further attention in future.

Copyright $\odot 2009$ S. Karger AG, Basel
\end{abstract}

\section{Introduction}

Double balloon enteroscopy (DBE) was introduced in 2001 by Yamamoto et al. [1] as a new endoscopic modality for visualization of the entire small bowel. Last year the single balloon enteroscopy (SBE) technique was introduced [2]. Recently, the term balloon-assisted enteroscopy (BAE) was introduced as a unifying terminology referring to both techniques [3]. In the current review, this new term will be used referring to DBE and/or SBE. BAE is now considered the standard endoscopic technique for visualization and endoscopic therapy of the small bowel. Complete small bowel evaluation is achieved in up to 25 and $86 \%$ of procedures in respectively SBE and DBE, mostly using the combined oral and rectal approach with tattoo or hemoclip marking $[2,4]$. The main advantages of BAE are controlled visualization, targeted biopsy sampling for pathologic evaluation and the ability to perform therapeutic interventions under direct endoscopic visualization. Currently, injection therapy, tattooing, argon plasma coagulation (APC), polypectomy, placement of (hemo-)clips, and dilation of strictures are considered standard interventions during a BAE procedure. In some cases pancreatico-biliary procedures can be performed using BAE, after surgical reconstructions that impede standard duodenoscopy. The introduction of larger diameter working channels in the latest versions of the enteroscopes, and the development of especially designed materials, have both led to easier

\section{KARGER}

Fax +4161306 1234

E-Mail karger@karger.ch

www.karger.com
(C) 2009 S. Karger AG, Basel

0257-2753/08/0264-0309 $\$ 24.50 / 0$

Accessible online at:

www.karger.com/ddi
Peter Mensink, MD, PhD

Department of Gastroenterology and Hepatology

Erasmus MC University Medical Center, PO Box 2040

NL-3000 CA Rotterdam (The Netherlands)

Tel. +31 10703 2385, Fax +31 10703 4680, E-Mail p.mensink@erasmusmc.nl 
Table 1. Therapeutic enteroscopic interventions using BAE: current indications and complication rates

\begin{tabular}{llll}
\hline Therapy & Indications & Complication rates \\
\cline { 3 - 4 } & & bleeding & perforation \\
\hline $\begin{array}{l}\text { Argon plasma } \\
\text { coagulation }\end{array}$ & $\begin{array}{l}\text { Vascular malformations/angiodysplasia } \\
\text { Tissue ablation }\end{array}$ & $0.4 \%$ & $1.2 \%$ \\
\hline Polypectomy & $\begin{array}{l}\text { Peutz-Jeghers syndrome } \\
\text { Familiar adenomatous polyps syndrome } \\
\end{array}$ & $3.3-4.3 \%$ & $0-6.5 \%$ \\
\hline Other polyposis syndromes, single polyps & & \\
\hline Pilation & Crohn's disease & $0 \%$ & $0-2.9 \%$ \\
Pancreatico-biliary & NSAID-related strictures & & - \\
\hline
\end{tabular}

access and advanced therapeutic opportunities in the small bowel.

In this review we will give an overview concerning the current possible therapeutic endoscopic interventions with BAE (table 1).

\section{Argon Plasma Coagulation}

APC is a method of non-contact electrocoagulation in which current is applied to tissues by means of ionized argon gas (argon plasma). BAE is widely used in evaluating the causes of obscure gastrointestinal bleeding (OGIB). Angiodysplasia, or arteriovascular malformations (AVMs), and tumors are the most important causes of OGIB [4-7]. APC of AVMs can lead to cessation of the gastrointestinal bleeding resulting in decrease or stop of transfusion requirements [5]. The real clinical impact of treatment of angiodysplasia or AVMs is currently a point of discussion: primary data concerning this issue showed promising results, but a recent study with longer followup has reported more disappointing results [8].

May et al. [9] showed that APC is also effective in hemostasis of Dieulafoy lesions in the small bowel. APC during BAE is also an applicable treatment of small and flat adenomas and can be used if these adenomas are endoscopically difficult to remove because of challenging position [10].

The energy levels used in APC treatment is of significant importance, in combination with the diameter of the APC probe for prevention of possible complications (i.e. perforation). A standard catheter diameter of $1.5 \mathrm{~mm}$
(4.5 Fr) in combination with energy levels of $30-40 \mathrm{~W}$ (APC 300/Erbotom ICC 200) or 15-25 W and pulse 2 mode (Vio APC 2, both Erbe Elektromedizin, Tübingen, Germany) seems safe $[9,10]$.

\section{Polypectomy}

Small bowel polyps and tumors are a common finding in patients undergoing BAE [11]. Small bowel polyps include hyperplastic polyps, adenomas mostly in relation with familial adenomatous polyposis and hamartomatous polyps associated with the Peutz-Jeghers syndrome (PJS). Before the introduction of BAE, patients with PJS underwent, mostly repeated, polypectomy or enterectomy during urgent or planned laparotomies. BAE is an effective approach to screen the whole small bowel for polyps and if indicated to remove these polyps. An additional indication for repeated polyp surveillance with BAE in these patients might be the malignancy rate of $2-3 \%$ for polyps $>1 \mathrm{~cm}[10,11]$. Eighteen polypectomies (varying in polyp size of 10-60 $\mathrm{mm}$ in diameter) during DBE were successfully performed in 2 patients with PJS, reported by Ohmiya et al. [12]. They concluded that PJS-associated complications (intussusception, bleeding and tumorigenesis) can be reduced by enteroscopic polypectomies [12]. May et al. [9] performed successfully 44 polypectomies for polyps ranging in diameter from 10 to $50 \mathrm{~mm}$. In PJS patients with endoscopic unresectable polyps or acute small bowel obstruction due to intussusception, laparotomy remains the first-choice treatment. 
Polypectomies can be carried out with a polypectomy snare after submucosal injection of the stalk of the polyp with a diluted epinephrine-saline solution $(1: 100,000)$. After resection, polyps can be captured with the polypectomy snare or a polyp retriever with a nitinol basket. Using a large-diameter overtube, the endoscope can be pulled back through the overtube outside the patient, with the overtube staying in position. After removal of the resected polyp, the endoscope can be reinserted via the overtube, resuming the enteroscopy. Adequate sedation by propofol or general anesthesia is preferred for these patients, in which the procedures are more timeconsuming and possibly more difficult by agitation of the patients [6].

So far, the experience of enteroscopic resection of flat adenomas or (early) cancers in the small bowel by BAE is limited. Only a few (case) reports have been published, describing resection of an early carcinoma in the afferent loop of a Roux-en-Y anastomosis and resection of a flat adenoma, both clinically successful $[6,13]$.

\section{Dilation Therapy}

Many chronic inflammatory diseases can cause strictures in the small bowel. Crohn's disease is one of the most common inflammatory diseases, often causing strictures in the small bowel. These strictures are mostly located in jejuno-ileal and ileal region (respectively 36 and $32 \%$ ), but can also be located more proximal in the small bowel $[9,14]$. BAE dilation therapy seems a safe and clinical useful alternative for, repeated, surgical therapy in these patients. Especially in patients with the need for repeated small bowel surgery, endoscopic dilation therapy might prevent short bowel problems in the future. Endoscopic dilation therapy can be performed using the 'through the endoscope' balloon dilation technique in enteroscopes with a large-diameter working channel. An alternative technique is placement of a guidewire through the stenosis, consequently removal of the endoscope (leaving the overtube in position) and insertion of a dilation balloon over the guidewire. After the dilation, the enteroscope can be reintroduced via the overtube, and the effect of treatment can be visualized. In general, all enteroscopic dilation procedures are performed using fluoroscopy guidance.

Fukumoto et al. [14] showed in a large series of small bowel strictures that in $87 \%$ of patients the lesions could be identified with DBE. They showed a success rate of $71 \%$ after dilation therapy ( $74 \%$ in the Crohn's stricture patients), after a mean follow-up of almost 12 months. The overall mean number of dilations was 1.6 per patient (1.5 in the Crohn's patients). Of the Crohn's disease stricture patients who had initial endoscopic dilation therapy, $17 \%$ had repeated dilation therapy and almost $9 \%$ eventually needed surgical therapy.

\section{ERCP Procedures}

Conventional endoscopic retrograde cholangiopancreaticography (ERCP) in patients after gastric or biliodigestive surgery can be challenging and is, depending on the type of surgery, often unsuccessful. Using BAE, deep insertion of these endoscopically difficult-to-reach bowel loops seems feasible, and diagnostic and therapeutic interventions of the pancreatico-biliary system can be performed [15-22]. Haruta et al. [15] reported the first treatment of a stricture in a hepaticojejunal anastomosis after liver transplantation in a child, using BAE. Repeated enteroscopic balloon dilations were necessary for a longterm success. More recently, Aabakken et al. [16] showed a success rate of $94 \%$ (17 out of 18 ) in reaching the end of the afferent limb of the Roux-en-Y anastomosis using BAE. They performed the majority of procedures (10 out of 13) in patients after liver transplantation for primary sclerosing cholangitis. A diagnosis was established in up to $85 \%$ of patients and therapy was successful in the majority of cases [17].

\section{Enteral Stent Placement}

Ross et al. [23] reported on the technique of enteral stent placement using BAE. In their case series, self-expanding metal stents were placed as a palliative measure in patients with stenosing small bowel tumors.

\section{Foreign Body Extraction}

DBE also enables the removal of foreign bodies from the small intestine making surgical intervention unnecessary. Numerous cases of successful retrieval of retained capsule endoscopes using the oral or anal approach are described in the current literature [24]. 


\section{Complications}

Recently, two large multicenter studies have presented data concerning complications and DBE $[25,26]$. The complication rate after diagnostic DBE procedures was $0.8 \%$ and comparable in both studies. The complication rate of therapeutic $\mathrm{DBE}$ procedures was $4.3 \%$, this rate being higher compared to therapeutic colonoscopy [25]. A single-center study by May et al., focusing especially on complications after therapeutic DBE, reported an overall complication rate of $3.4 \%$. In the latter study a rather high complication rate of $10.8 \%$ was reported after polypectomy [9]. In the international multicenter study, one acute pancreatitis was reported after a pancreatico-biliary intervention in a patient with a Roux-en-Y biliodigestive anastomosis. Several other case reports document the risk of complications after therapeutic interventions using DBE $[27,28]$. The first two published series concerning SBE procedures reported both one complication, accounting for a complication rate of 1.2 and $2.7 \%$, respectively $[2,29]$.

\section{Conclusions}

The introduction of $\mathrm{BAE}$ has given the endoscopist the opportunity to perform therapeutic endoscopic interventions in all regions of the small bowel. In a short time, therapeutic BAE has evolved to a wide range of different endoscopic therapies. In the past few years a lot of experience has been gathered, especially concerning APC treatment (AVMs and angiodysplasia), polypectomy (PJS), dilation therapy (Crohn's disease) and ERCP procedures in patients with surgically altered proximal intestinal anatomy. These BAE therapeutic interventions seem of clinical benefit in selected patients, although currently controversy exists about the long-term outcome following endoscopic therapy in OGIB patients. Hopefully in the coming years prospective studies will give answers concerning this interesting clinical problem. The clinical impact of dilation of small bowel Crohn's disease strictures and polypectomies in the PJS appears to be evident, but larger and longer follow-up studies after therapy have to be conducted. The concomitant introduction of antiTNF- $\alpha$ medication in Crohn's disease patients treated with dilation therapy for small bowel strictures can possibly improve the outcome in these patients. The overall complication rate of therapeutic BAE seems acceptable, but is slightly higher compared to therapeutic colonoscopy. Further improvement of enteroscopy techniques, endoscopic materials and patient sedation methods will hopefully lead to a higher clinical impact and lower complication rate of therapeutic BAE in future.

\section{References}

1 Yamamoto H, Sekine Y, Sato Y, Higashizawa T, Miyata T, Iino S, et al: Total enteroscopy with a nonsurgical steerable double-balloon method. Gastrointest Endosc 2001;53:216220.

-2 Tsujikawa T, Saitoh Y, Andoh A, Imaeda H, Hata K, Minematsu H, et al: Novel singleballoon enteroscopy for diagnosis and treatment of the small intestine: preliminary experiences. Endoscopy 2008;40:11-15.

3 Mönkemüller K, Fry LC, Bellutti M, Malfertheiner P: Balloon-assisted enteroscopy: unifying double-balloon and single-balloon enteroscopy. Endoscopy 2008;40:537.

4 Zhong J, Ma T, Zhang C, et al: A retrospective study of the application on double-balloon enteroscopy in 378 patients with suspected small-bowel diseases. Endoscopy 2007;39:208-215.
Kwan V, Bourke MJ, Williams SJ, Gillespie PE, Murray MA, Kaffes AJ, et al: Argon plasma coagulation in the management of symptomatic gastrointestinal vascular lesions: experience in 100 consecutive patients with long-term follow-up. Am J Gastroenterol 2006;101:58-63.

-6 Kaffes AJ, Siah C, Koo JH: Clinical outcomes after double-balloon enteroscopy in patients with obscure gastrointestinal bleeding and a positive capsule endoscopy. Gastrointest Endosc 2007;66:304-309.

7 Sun B, Rajan E, Cheng S, Shen R, Zhang C, Zhang S, et al: Diagnostic yield and therapeutic impact of double-balloon enteroscopy in a large cohort of patients with obscure gastrointestinal bleeding. Am J Gastroenterol 2006;101:2011-2015.

8 Madisch A, Schmolders J, Brückner S, Aust D, Miehlke S: Less favorable clinical outcome after diagnostic and interventional double balloon enteroscopy in patients with suspected small-bowel bleeding? Endoscopy 2008;40:731-734. $\checkmark 9$ May A, Nachbar L, Pohl J, Ell C: Endoscopic interventions in the small bowel using double balloon enteroscopy: feasibility and limitations. Am J Gastroenterol 2007;102:527-535.

10 Mönkemüller K, Fry LC, Ebert M, et al: Feasibility of double-balloon enteroscopy-assisted chromoendoscopy of the small bowel in patients with familial adenomatous polyposis. Endoscopy 2007;39:52-57.

11 Fry LC, Neumann H, Kuester D, Kuhn R, Bellutti M, Malfertheiner P, Mönkemüller K: Small bowel polyps and tumours: endoscopic detection and treatment by double-balloon enteroscopy. Aliment Pharmacol Ther 2008 , in press.

12 Ohmiya N, Taguchi A, Shirai K, Mabuchi N, Arakawa D, Kanazawa H, et al: Endoscopic resection of Peutz-Jeghers polyps throughout the small intestine at double-balloon enteroscopy without laparotomy. Gastrointest Endosc 2005;61:140-147. 
-13 Kuno A, Yamamoto H, Kita H, Sunada K, Yano T, Hayashi Y, et al: Double-balloon enteroscopy through a Roux-en-Y anastomosis for EMR of an early carcinoma in the afferent duodenal limb. Gastrointest Endosc 2004; 60:1032-1034.

- 14 Fukumoto A, Tanaka S, Yamamoto H, Yao T, Matsui T, Iida M, et al: Diagnosis and treatment of small-bowel stricture by double balloon endoscopy. Gastrointest Endosc 2007; 66:S108-S112.

15 Haruta H, Yamamoto H, Mizuta K, Kita Y, Uno T, Egami S, et al: A case of successful enteroscopic balloon dilation for late anastomotic stricture of choledochojejunostomy after living donor liver transplantation. Liver Transpl 2005;11:1608-1610.

-16 Aabakken L, Bretthauer M, Line PD: Double-balloon enteroscopy for endoscopic retrograde cholangiography in patients with a Roux-en-Y anastomosis. Endoscopy 2007; 39:1068-1071.

17 Maaser C, Lenze F, Bokemeyer M, Ullerich H, Domagk D, Bruewer M, et al: Double balloon enteroscopy: a useful tool for diagnostic and therapeutic procedures in the pancreaticobiliary system. Am J Gastroenterol 2008; 103:894-900.
18 Chu YC, Yang CC, Yeh YH, Chen CH, Yueh SK: Double-balloon enteroscopy application in biliary tract disease - its therapeutic and diagnostic functions. Gastrointest Endosc 2008;68:585-591.

19 Moreels TG, Roth B, Vandervliet EJ, Parizel PM, Dutré J, Pelckmans PA: The use of the double-balloon enteroscope for endoscopic retrograde cholangiopancreatography and biliary stent placement after Roux-en-Y hepaticojejunostomy. Endoscopy 2007;39 (suppl 1):E196-E197.

20 Koornstra JJ: Double balloon enteroscopy for endoscopic retrograde cholangiopancreaticography after Roux-en-Y reconstruction: case series and review of the literature. Neth J Med 2008;66:275-279.

21 Fähndrich M, Sandmann M, Heike M: A facilitated method for endoscopic interventions at the bile duct after Roux-en-Y reconstruction using double balloon enteroscopy. Z Gastroenterol 2008;46:335-338.

22 Mönkemüller K, Fry LC, Bellutti M, Neumann H, Malfertheiner P: ERCP using single-balloon instead of double-balloon enteroscopy in patients with Roux-en-Y anastomosis. Endoscopy 2008;40:E19-E20.

23 Ross AS, Semrad C, Waxman I, Dye C: Enteral stent placement by double balloon enteroscopy for palliation of malignant small bowel obstruction. Gastrointest Endosc 2006;64:835-837.
24 Rejchrt S, Kopacova M, Tacheci I, Bures J: Interventional DBE for Crohn's, gastrointestinal bleeding and foreign body extraction. Tech Gastrointest Endosc 2008;10:101-106.

-25 Mensink PB, Haringsma J, Kucharzik T, Cellier C, Pérez-Cuadrado E, Mönkemüller K, et al: Complications of double balloon enteroscopy: a multicenter study. Endoscopy 2007; 39:613-615.

-26 Möschler O, May AD, Müller MK, Ell C; DBE-Studiengruppe Deutschland: Complications in double-balloon enteroscopy: results of the German DBE register. Z Gastroenterol 2008;46:266-270.

27 Spahn TW, Kampmann W, Eilers M, et al: Small-bowel perforation after endoscopic resection of a Peutz-Jeghers polyp in an infant using double-balloon enteroscopy. Endoscopy 2007;39:E217.

28 Matsushita M, Shimatani M, Uchida K, et al: Mechanism of acute pancreatitis after peroral double-balloon enteroscopy. Endoscopy 2007;39:480-481.

29 Kawamura T, Yasuda K, Tanaka K, Uno K, Ueda M, Sanada K, Nakajima M: Clinical evaluation of a newly developed single-balloon enteroscope. Gastrointest Endosc 2008;68:1112-1116. 